\title{
Dynamic Kinetic Resolution Strategy for the Asymmetric Nickel-Catalyzed Capture of Transient Cyclic Allenes
}

\section{Key words}

nickel catalysis

cyclic allenes

enantioselectivity

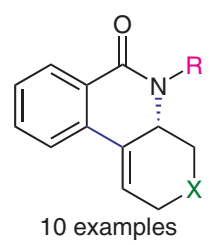

up to $85 \%$ yield, $94 \%$ ee

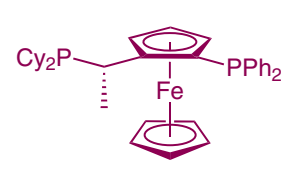

(S)-(R)-Josiphos

$(0.1 \mathrm{mmol})$

(1 equiv)<smiles>O=C1c2ccccc2C2=CCN(C(=O)O)C[C@@H]12</smiles><smiles>O=C1c2ccccc2C2=CC[N+](C(=O)O)C[C@@H]2N1Cc1ccccc1</smiles>

$66 \%$ yield, $84 \%$ ee<smiles>CN1C(=O)c2ccccc2C2=CCCCC21</smiles>

$78 \%$ yield, $88 \%$ ee<smiles>CN1C(=O)c2ccccc2C2=CCOCC21</smiles>

$84 \%$ yield, $81 \%$ ee

$63 \%$ yield, $81 \%$ ee

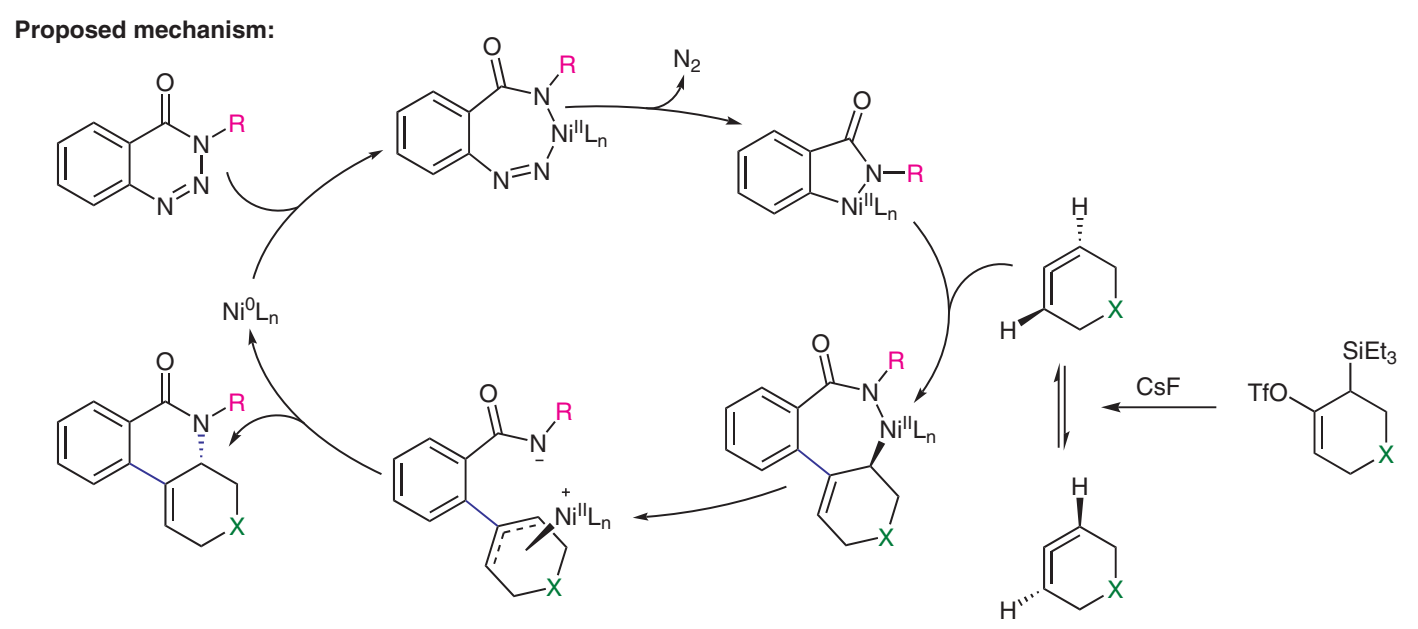

Significance: Taking advantage of the rapid racemization of strained cyclic allenes, a dynamic kinetic resolution strategy was used for the enantioselective nickel-catalyzed interception of the shortlived cyclic allenes using denitrogenative annulation of benzotriazinones. Starting from racemic silyl triflates, both racemic and enantioselective versions of the reaction were investigated, producing a variety of phenanthridinone products in good yield and enantioselectivity. Notably, olefin isomerization to restore aromaticity was not observed.
Comment: DFT studies were used to elucidate the reaction mechanism, and showed that direct reductive elimination does not follow the migratory insertion step as expected, since it would give rise to the opposite enantiomer of the product. Instead, the authors propose isomerization from the $\sigma$-nickel allyl species to a prochiral $\pi$-allyl species, with subsequent outer-sphere nucleophilic attack by the amidate anion, leading to the observed product. 